\title{
Evaluation of Energy Savings of Daylight-Linked Lighting Control Strategies Using Different Sky Distribution Models
}

\author{
Wenqiang CHEN ${ }^{1}$, Danny H W LI ${ }^{1}$, Shuyang $\mathrm{LI}^{1}$ \\ ${ }^{1}$ Building Energy Research Group, Department of Architecture and Civil Engineering, City \\ University of Hong Kong, Tat Chee Avenue, Kowloon, Hong Kong SAR, China
}

\begin{abstract}
Among all components of building energy use, the energy consumption caused by electric lighting can account for more than one quarter. Daylight are more preferable than artificial lighting since its quality is the one light source that most closely matches human visual response. Daylight-linked lighting control strategies can effectively reduce the electricity consumption of lighting. The daylight illuminance inside and outside a room are largely determined by the sky luminance distributions. However, the actual sky conditions are more complicated because of the changeable weather. The sky luminance distributions models could be very helpful for predicting the sky conditions. The Perez All-weather model and the CIE (International Commission on Illumination) Standard Sky model are the two most famous and widely used approaches to provide a framework for representing actual sky conditions. This study aims to evaluate the energy saving potential of daylight-linked lighting control strategies using the above models. RADIANCE was used as the simulation engine for daylight illuminance, while EnergyPlus was used to evaluate the energy savings. The simulation results of vertical illuminance were analysed and compared with the measured data. Lighting schedules derived from the interior daylighting levels were imported to the energy models. Results showed that at least 55\% lighting energy and 9\% cooling energy reduction can be achieved using daylight dimming controls based on the two sky luminance distribution models. The findings and implications were discussed.
\end{abstract}

Keywords: Daylighting, Energy simulation, Lightingcontrol, Energy efficient.

\section{Introduction}

Building energy accounts for a large amount of total energy consumption of the society. In densely built cities such as Hong Kong, almost $90 \%$ of total electricity consumption is contributed by buildings (EMSD., 2018). Electric lighting is commonly used to create visually comfortable interior environment, especially for office buildings. Among all components of energy use in commercial buildings, the electric lighting can account for about $20 \%-30 \%$ of total electricity use (Chow et al., 2013). Daylight is more preferable than artificial lighting since it can provide both the visual comfort and good colour rendering. Daylighting is an effective and sustainable development strategy for achieving energy- efficiency (Li et al., 2013). Photoelectric lighting controls, such as dimming controls, can effectively reduce the lighting energy consumption without deteriorating the visual comfort. The precision of the lighting control depends on the accuracy of the indoor illumination levels obtained. Without direct measurements, lighting simulation results could be used for evaluating daylightlinked lighting controls.

The daylight illuminance inside a room is largely determined by the illuminance levels received by the vertical fenestrations and the vertical illuminance is mainly determined by the sky luminance distribution patterns $(\mathrm{Li}, 2010)$. However, the actual sky conditions are more complicated and less predictable because of the changeable weather. Thus, in the absence of measurements, sky luminance distribution models could be very helpful for predicting the actual sky conditions. The choice of different sky luminance distribution models for calculating the daylight illuminance is rarely considered in practices of energy and daylighting simulations. In this study, two most famous and widely used sky luminance distribution models were evaluated to predict the vertical and indoor daylight illuminance. Sky luminance distributions and horizontal and vertical illuminance data in 10-min interval measured in 2005 were analysed for this study. The predicted vertical illuminance was compared with the measured data and the errors were presented. A daylight-linked lighting control strategy based on the indoor illuminance predicted by the above two sky models was applied to a reference office building. The lighting and cooling energy saving potentials were studied. RADIANCE was used to simulate the daylight illuminance, while EnergyPlus was used to evaluate the energy savings. The findings are significant for daylighting and energy-efficient building designs.

\section{Sky Luminance Distribution Models \\ CIE Standard General Sky Model}

The International Commission on Illumination (CIE) has adopted a list of 15 standard skies in 2003 to provide a classic overall framework for representing actual sky conditions (CIE, 2003). The Standard General Sky Model was first proposed by Kittler (1997). The model was also recognized by the International Organisation for Standardisation (ISO). Each standard sky represents a unique and well-defined sky luminance pattern which models the sky under a wide range of conditions, from the 
heavily overcast sky to cloudless weather. The standard intends to provide a universal basis for the classification of measured sky luminance distributions and to give a method for calculating sky luminance in daylighting design procedures. The luminance distribution for each CIE standard sky can help in determining the daylight illuminance on any inclined surfaces; this is particularly useful for variously oriented vertical planes. Since daylight is the visible part of solar irradiance, the same calculation procedures for computing daylight illuminance based on standard sky classifications can also be applied to predict sky irradiance (Li and Lou, 2018). The mathematical expression of the standard predicts the ratio of the luminance of an arbitrary sky element $\left(L_{a}\right.$, $\left.\mathrm{cd} / \mathrm{m}^{2}\right)$ to the zenith luminance $\left(L z, \mathrm{~cd} / \mathrm{m}^{2}\right)$ with a relative gradation function $\varphi(Z) / \varphi\left(0^{\circ}\right)$ and a relative scattering indicatrix function $f(\chi) / f\left(Z_{S}\right)$. The gradation function assumes a smooth luminance gradation between horizon and zenith. The scattering function indicates the direct sunlight scattering in the atmosphere, brightness of a sky element changes with the scattering angle. Both gradation and indicatrix functions are of six types covering overcast to clear skies. The combinations can generate many sky types but only 15 relevant were selected to be the standard set. The equations are given as follows:

$$
\begin{gathered}
L_{R}=\frac{L_{a}}{L_{Z}}=\frac{\varphi(Z)}{\varphi\left(0^{\circ}\right) \frac{f(\chi)}{f\left(Z_{S}\right)}} \\
\frac{\varphi(Z)}{\varphi\left(0^{\circ}\right)}=\frac{1+a \exp (b / \cos Z)}{1+a \exp b} \\
\frac{f(\chi)}{f\left(Z_{S}\right)}=\frac{1+c\left[\exp (d \chi)-\exp \left(\frac{d \pi}{2}\right)\right]+e \cos ^{2} \chi}{1+c\left[\exp \left(d Z_{S}\right)-\exp \left(\frac{d \pi}{2}\right)\right]+e \cos ^{2} Z_{S}}
\end{gathered}
$$

where $L_{R}$ is the relative sky luminance of an arbitrary sky element, $Z$ and $Z_{S}$ are the zenith angle of the sky element and the sun (rad); $\chi$ is the scattering angle in degree (the shortest angle between the sun and the sky element); $a, b$, $\mathrm{c}, \mathrm{d}$ and $\mathrm{e}$ are the coefficients specified by each 15 standard sky type, see Appendix. $\chi$ can be obtained by the following equation:

$\chi=\arccos \left(\cos Z_{S} \cos Z+\sin Z_{S} \sin Z \cos \left|\phi-\phi_{S}\right|\right)(4)$ where $\phi$ and $\phi_{S}$ are the azimuth angle of the sky element and the sun (rad). Figure 1 shows the angles defining the position of a sky element and the sun.

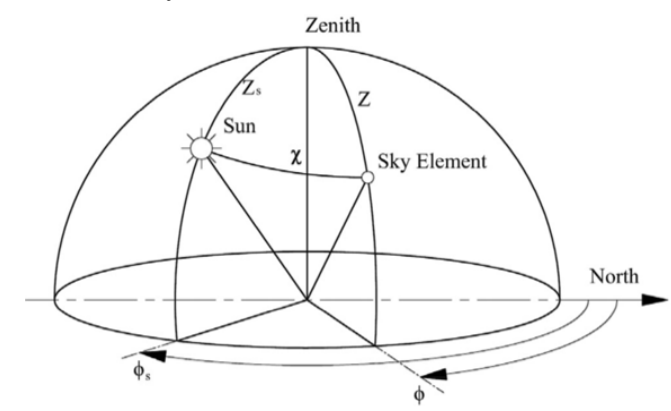

Figure 1: The angles defining the position of a sky element and the sun.

\section{Perez All-weather Model}

The Perez All-weather Model also refers to Perez All-sky Model or Perez 1993 Model (Perez, Seals and Michalsky, 1993). The model retains a mathematical expression that is a generalization of the CIE clear sky formula which includes five adjustable coefficients to account for luminance distributions. The relative luminance can be described by:

$$
\begin{gathered}
L_{R}=\frac{f(Z, \chi)}{f\left(0^{\circ}, Z_{S}\right)}= \\
\frac{[1+a \exp (b / \cos Z)] \times\left[1+c \exp (d \chi)+e \cos ^{2} \chi\right]}{[1+a \exp (b)] \times\left[1+c \exp \left(d Z_{S}\right)+e \cos ^{2} Z_{S}\right]}
\end{gathered}
$$

The Perez All-weather model is designed to use hourly or shorter time step global and direct irradiance to predict sky luminance angular distribution. It is similar to CIE Standard General Sky Model except the adjustable coefficients are parameterized of insolation conditions. Three variables are used to determine the five coefficients, namely solar zenith angle $\left(Z_{S}\right)$, the sky's clearness $(\varepsilon)$ and sky brightness $(\Delta)$. The equations are given as follows:

$$
\begin{gathered}
\varepsilon=\frac{\left[\frac{I_{h d}+I_{B}}{I_{h d}}+1.041 Z_{S}{ }^{3}\right]}{\left(1+1.041 Z_{S}^{3}\right)} \\
\Delta=\left(m I_{h d}\right) / E I_{O B}
\end{gathered}
$$

where $I_{h d}$ is the horizontal diffuse irradiance $\left(\mathrm{W} / \mathrm{m}^{2}\right), I_{B}$ is the direct normal irradiance $\left(\mathrm{W} / \mathrm{m}^{2}\right), I_{O B}$ is the direct normal extraterrestrial irradiance $\left(\mathrm{W} / \mathrm{m}^{2}\right)$ and $m$ is the optical airmass.

The five coefficients of the model are treated as functions of the above parameters. The functions are analytical in terms of $\Delta$ and $Z_{S}$ and discrete in terms of $\varepsilon$. For each coefficient, a total of eight functions of $\Delta$ and $Z_{S}$ corresponding to eight sky clearness intervals are derived. The eight intervals of $\varepsilon$ represent eight categories of sky clearness from overcast sky $(1<\varepsilon<1.065)$ to very clear sky $(\varepsilon>6.2)$. The $\Delta$ and $Z_{S}$ analytical form is the same for each coefficient at individual $\varepsilon$ interval, as described as follows:

$$
x=x_{1}+x_{2} Z_{S}+\Delta\left(x_{3}+x_{4} Z_{S}\right)
$$

where $x$ denotes the five coefficients in Equation (5), $x_{i}$ are coefficients determined by the intervals of $\varepsilon$. The two exceptions are for the coefficients $\mathrm{c}$ and $\mathrm{d}$ in the first $\varepsilon$ interval $(1,1.065)$. These functions are:

$$
\begin{array}{r}
c=\exp \left[\left(\Delta\left(c_{1}+c_{2} Z_{S}\right)\right)^{c_{3}}\right]-c_{4} \\
d=-\exp \left[\Delta\left(d_{1}+d_{2} Z_{S}\right)\right]+d_{3}+\Delta d_{4}
\end{array}
$$

For details and all the values of the coefficient $x_{i}$, can be found in (Perez, Seals and Michalsky, 1993).

For daylighting calculation purposes, the sky absolute luminance distributions can be obtained with values of zenith luminance or of horizontal irradiance/illuminance by both CIE model and Perez's model.

\section{Data measurements}

The measurements of daylight illuminance and sky luminance data made in 2005 were used for this study. The measurements were made at a station on the top-roof 
of a campus building in Hong Kong. The illuminance data includes global and diffuse outdoor illuminance on a horizontal plane, and vertical global illuminance at the four cardinal orientations (N, E, S and W). Six illuminance sensors (T-10M) were mounted on the rooftop in a position relatively free from obstructions and easily for maintenance. The measurement interval of illuminance data is $1 \mathrm{~min}$ and was averaged to $10 \mathrm{~min}$ interval to make a consistence with the sky luminance data.

The sky luminance distributions were measured by a sky scanner (EKO MS-300LR), which was manufactured and calibrated by the EKO Company of Japan. It measures the luminance of 145 sky patches by rotating the sensor head in both altitude and azimuth directions. The number of each sky patch and its altitude and azimuth angles are shown in Figure 2. Each complete scanning cycle took about $4 \mathrm{~min}$ and corresponding measurements were taken every $10 \mathrm{~min}$. Details of the daylight illuminance and sky luminance measurements can be found in earlier works (Li, 2005). Data collection started before sunrise and finishes after sunset. The output data from the illuminance sensors and scanner were transmitted and recorded using data-management software on a microcomputer placed inside the laboratory space at the top floor. To eliminate spurious data and erroneous measurements which may be caused by instrumentation malfunction, power failure or senor calibration, quality control tests based on CIE guidance (CIE, 1994) were carried out. After the quality control tests, around 14000 datasets were retained for analysis.

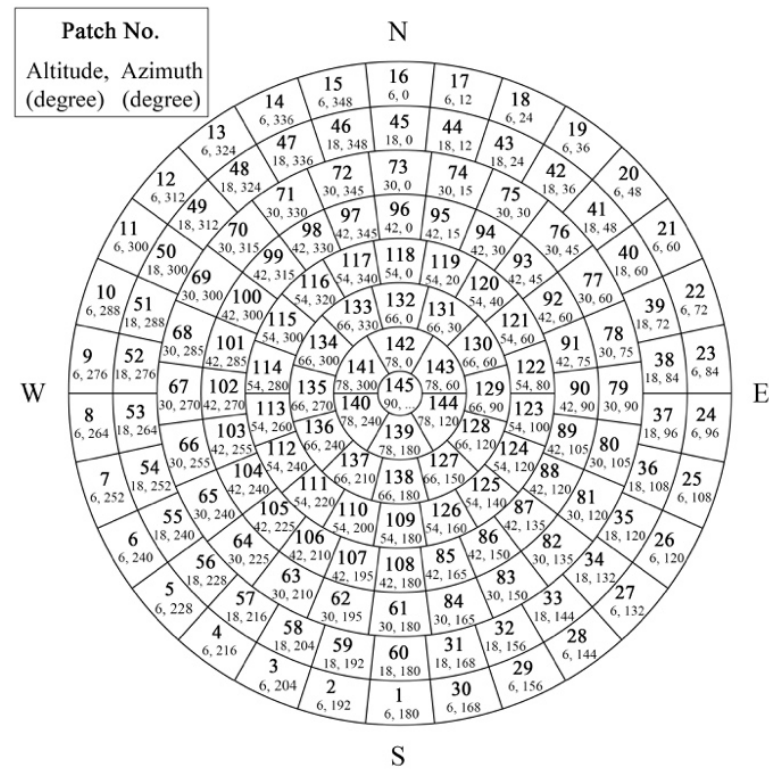

Figure 2: Measurement points of each sky patch and its altitude and azimuth angels.

\section{Reference building}

To evaluate the effects of photoelectric lighting control strategy using the two sky luminance distribution models, an office building was selected as the reference building for the analysis. The geometry of the reference building was derived from the Commercial Reference Buildings of
US (DOE, 2019). The reference buildings also known as commercial building benchmark models which can provide complete descriptions for whole building energy analysis and research. The medium size office building was selected for the analysis. It has three stories, each floor has five zones including one core zone and 4 perimeter zones, all zones are assumed to be office space. Since there would be no daylight reach the core zone, the lighting energy and cooling energy analysis was carried out for the four perimeter zones. Figure 3 illustrates the perspective view of the reference office building.

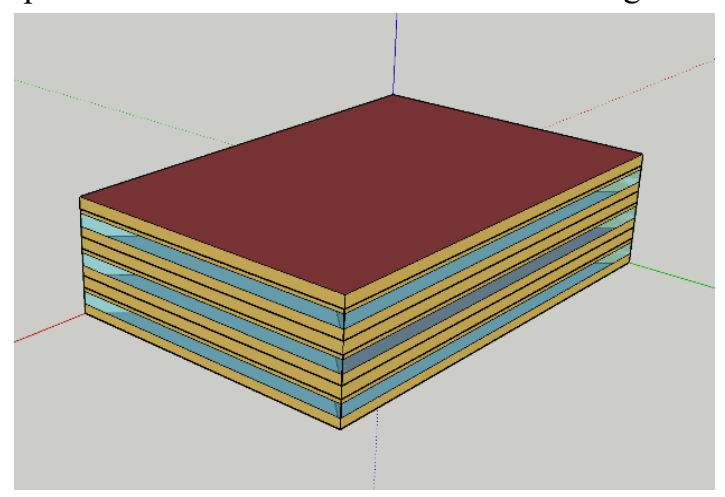

Figure 3: Perspective view of the reference building.

The areas of the north/south zone and the east/west zone for each floor are $207 \mathrm{~m}^{2}$ and $131 \mathrm{~m}^{2}$, respectively. The floor to floor height is $3.96 \mathrm{~m}$ and floor to ceiling height is $2.74 \mathrm{~m}$. The window sill height is $1 \mathrm{~m}$ from the floor. The window to wall ratio (WWR) for each zone is 0.33 , and the windows are assumed to be evenly distributed along the perimeter walls. Properties of the building envelope and parameters of the interior surfaces are summarized in Table 1.

Table 1: Parameters of building envelope.

\begin{tabular}{|c|c|c|c|c|}
\hline & $\begin{array}{c}\text { U-value } \\
\left(\mathrm{W} \mathrm{m}^{-2} \mathrm{~K}^{-1}\right)\end{array}$ & $\begin{array}{c}\text { Reflec } \\
\text {-tance }\end{array}$ & SHGC & $\begin{array}{c}\text { Transmitt } \\
\text {-ance }\end{array}$ \\
\hline Roof & 0.358 & 0.7 & - & - \\
\hline Wall & 0.704 & 0.5 & - & - \\
\hline Floor & 1.862 & 0.3 & - & - \\
\hline Window & 5.835 & 0.4 & 0.251 & 0.6 \\
\hline
\end{tabular}

Table 2 gives the occupant densities, equipment and lighting electricity densities, fresh airflow rate for each zone, which can meet the criteria specified by ASHRAE Standard 62.1-2007 (ASHRAE, 2007) and Hong Kong building energy code BEC-2018 (EMSD, 2018).

Table 2: Internal loads of the reference building.

\begin{tabular}{|c|c|}
\hline Occupancy & Equipment \\
\hline $18.6\left(\mathrm{~m}^{2} /\right.$ person $)$ & $10.8\left(\mathrm{~W} / \mathrm{m}^{2}\right)$ \\
\hline Lighting & Fresh air \\
\hline $6.7\left(\mathrm{~W} / \mathrm{m}^{2}\right)$ & $0.0125(\mathrm{~m} 3 / \mathrm{s} /$ person $)$ \\
\hline
\end{tabular}

A VAV (variable air volume) system with water-cooled chiller was installed to serve the reference building. Single duct air terminal and dual cooling coil were used and the COP (coefficient of performance) of the systems is 3.23 which can meet the requirements of the standard (ASHRAE, 2007). Zone cooling air temperature was set 
to $25.5^{\circ} \mathrm{C}$ according to the local suggestions (EMSD, 2018). The zone cooling design supply air temperature was $12.8{ }^{\circ} \mathrm{C}$ and the constant minimum air flow fraction was 0.3 . The daily operation, occupancy, equipment and HVAC schedules were referred to the office buildings and followed the specifications of the standard. Other settings were followed the default of the original benchmark models except for the lighting schedules.

The energy-efficient T5 fluorescent lamps with an efficacy of $75 \mathrm{~lm} / \mathrm{W}$ were used and it can keep the illuminance levels of office space at 500 lux which can meet the criteria. High frequency continuous dimming controls based on the daylight illuminance at the photoelectric sensors were adopted to reduce the energy consumption of electric lighting of the perimeter zones of the reference building. The photoelectric sensors were installed at the centers of four perimeter zones of each floor. The height of the sensors was 1 meter from the floor, which was consistent with the height of common working planes. The plan view of the reference office building and the positions of the photoelectric sensors are illustrated in Figure 4.

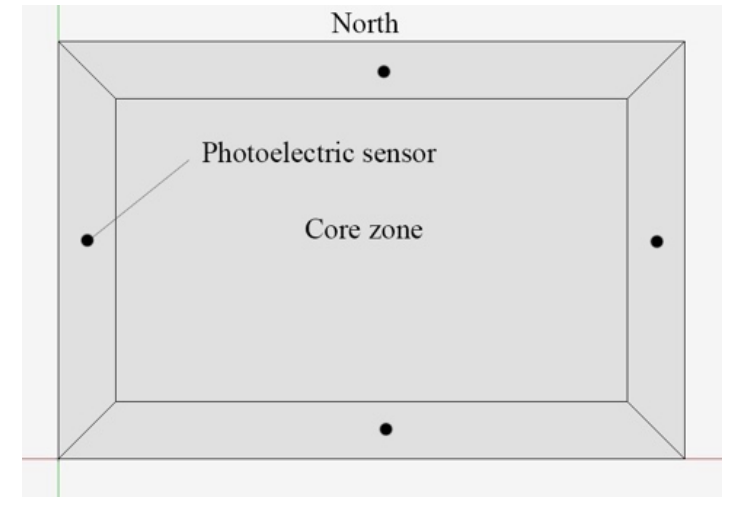

Figure 4: Plan view of the reference building and position of photoelectric sensors.

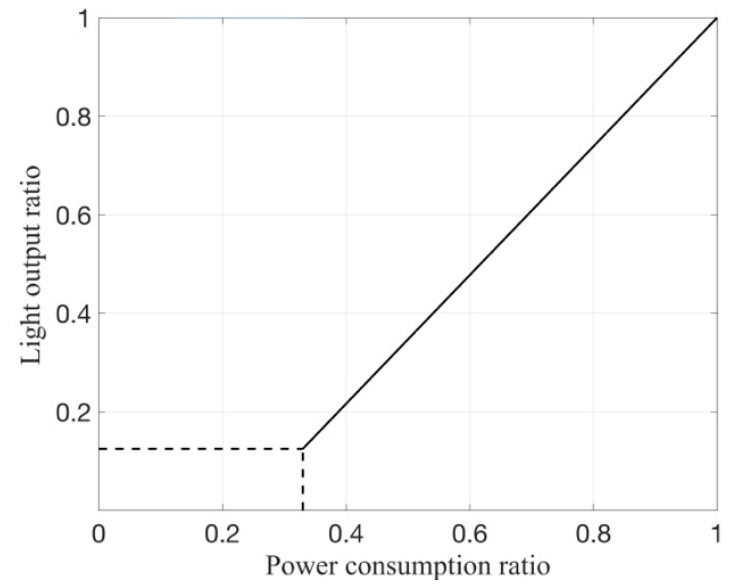

Figure 5: Relationship between power consumption ratio and light output ratio of the dimming control.

It is assumed that the dimming control have the ideal characteristic of light output being perfectly proportional to power consumed. The lamps cannot be dimmed to total extinction, a minimum light output ratio of $12.5 \%$ and a minimum consumed power ratio of $33 \%$ was used in this study. Figure 5 shows the relationship between the power consumption ratio and the light output ratio of the dimming system. The target illuminance was set to 500 lux for the reference office building. The daylight-linked lighting controls can dim down the electric lighting when the daylight level surpass the target illuminance. The dimming controls are more preferable than simple on-off daylight-linked lighting control which can disturb occupants and shorten the lamp life. Dimming controls vary the light output of lamps in accordance with the prevailing daylight level, which can avoid the rapid and frequent switching of lights on and off, particularly during unstable weather conditions when daylight levels are fluctuating around the target illuminance (Li, et al., 2015).

\section{Simulation approach}

The lighting simulation programme RADIANCE (Ward, and Shakespeare, 1998) was used to calculate the vertical and indoor illuminance. It is a sophisticated lighting visualisation system. The package employs backward raytracing algorithms to calculate the light received by a given point. It has been reported that RADIANCE could accurately simulate interior illuminance for a range of realistic sky conditions. The latest version (5.2) of RADIANCE was used in this study. The measured horizontal illuminance data were selected as the inputs for both sky models to acquire the sky luminance distribution patterns.

EnergyPlus (DOE, 2019) is a whole building energy simulation software to model both energy consumption for heating, cooling, ventilation and lighting and process loads. EnergyPlus has the potential to be the most accurate method of solving for the heating and cooling loads in a building because it accounts for all energy flows in their most basic, fundamental form and does not impose any simplifications on the solution technique (Wang and Zhai, 2016). It also supports sub-hourly, userdefinable time steps for schedules and it automatically varied time steps for interactions between thermal zones and HVAC systems. These allow EnergyPlus to model systems with fast dynamics while also trading off simulation speed for precision. Thus, EnergyPlus was used to evaluate the lighting and cooling energy of the reference building.

\section{Results}

The two sky luminance distribution models were used to predicted the vertical illuminance, and their performance was assessed by comparing with measured data. The daylight illuminance at the positions of four photoelectric sensors were also calculated with the two different sky models. Then, the dimming lighting control was applied to each perimeter zones of the reference office building respectively. The lighting and cooling energy saving potentials were compared.

\section{CIE standard sky classification}

Since the coefficients to calculate relative sky luminance for the CIE Standard General Sky Model are constants for each standard sky type, it is necessary to classify the skies 
into the 15 Standard Sky. The measured sky luminance and the horizontal diffuse illuminance data were used for sky classification. As the modelled sky luminance distributions were in relative values, each scanned luminance value should be normalized to the horizontal diffuse illuminance by multiplied by a normalisation ratio. The standard sky interpreted is the one with the lowest root mean square error (RMSE) between the predicted luminance values by each set of standard skies and the measured values. Detailed calculations of the process can be found in ( $\mathrm{Li}$ et al., 2014). Figure 6 summarizes the occurrence of each sky type. It indicates that Sky 1, 8 and 13 accounts for about $70 \%$ of all the sky conditions.

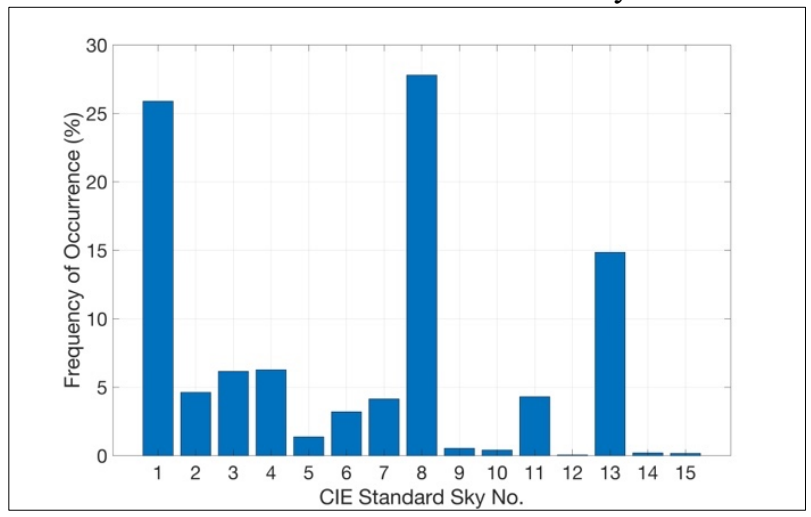

Figure 6: Occurrence of each CIE Standard Sky.

\section{Vertical illuminance}

The vertical global illuminance $\left(E_{V g}\right)$ on the four cardinal surfaces facing the north, east, south and west can be determined using the following equation:

$$
E_{V g}=E_{V d}+E_{V b}+E_{V r}
$$

where $E_{V d}$ is the vertical diffuse illuminance (Lux), $E_{V b}$ is the direct illuminance (Lux) and $E_{V r}$ is the groundreflected illuminance (Lux).

Calculation of the direct illuminance is quite straight forward, given the position of the sun and the orientation of the surface. The ground-reflected illuminance depends on the average ground reflectivity ( 0.2 in this study), it is assumed that vertical surface receives half of the total solar illuminance reflected isotropically from the ground. The mathematical equations of the above two components can be found in (Li et al., 2005). The critical issue would be the handling of the sky-diffuse component which depends on the sky luminance levels and distributions. It has been pointed out that the sky-diffuse component is considered as the largest potential source of computational error. The diffuse illuminance on an inclined plane can be obtained by integrating the luminance distribution of the sky dome 'seen' by the plane. The sky luminance data predicted by CIE Standard General Sky Model and Perez All-sky Model can be generated from the horizontal measurements of illuminance. The luminance of each sky patch adopted by RADIANCE was taken from the two sky models separately, and the global illuminance on four vertical surfaces were simulated. The RMSEs (in percentage) against the measured data were calculated and the results are shown in Figure 7.

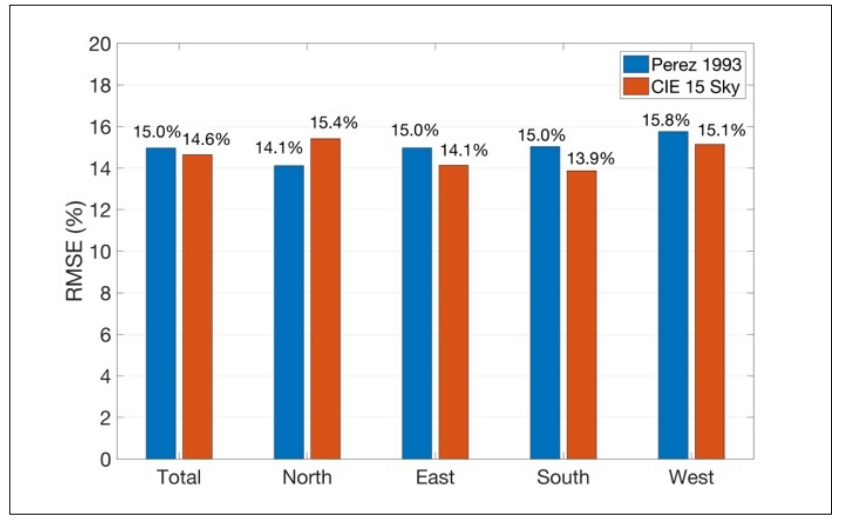

Figure 7: Errors of predicted vertical global illuminance against measurements.

In general, the error of predict vertical global illuminance are less than $15.8 \%$ for all the directions. The overall performance of the CIE model is slightly better than that of the Perez model. The RMSEs are $15 \%$ for the Perez 1993 model and $14.6 \%$ for the CIE Standard Sky model. As for the four directions, vertical illuminance data on east, south and west surfaces predicted by the CIE model are more accurate than those of the Perez model.

\section{Lighting and cooling energy}

The two sky luminance distribution models were also evaluated in terms of indoor daylighting illuminance. RADIANCE was also used for simulating the indoor illuminance at the positions of photoelectric sensors installed in each perimeter zone of the reference building. Profiles of daylight illuminance data in $10 \mathrm{~min}$ interval were made according to the simulation results.

The lamps can produce a visual comfort indoor environment, but they will also emit radiation into the space, which will become a part of internal cooling loads. Daylight-linked lighting controls can not only reduce the lighting electricity consumption but also can help to reduce the cooling energy of the building. Since the target illuminance was set to 500 lux, when there is no daylight, the light output of the lamps would be 500 lux at the full power, and when the daylight level exceeds 500 lux, the lamps would work at $33 \%$ of the full power. If the daylight illuminance is less than 500 lux, the lamps will be adjusted to a proper level to compensate the daylight to keep the illuminance of the space at 500 lux. Thus, profiles of actual lighting schedules distinguished from the original lighting schedules can be obtained based on the simulated daylight illuminance.

Then, the 10-min lighting schedules generated using different sky luminance distribution models were imported to EnergyPlus to conduct the simulations. The annual lighting energy consumption and annual cooling energy consumption of the four perimeter zones were acquired. The lighting energy and cooling energy in each floor were summed up according to each direction. The simulation results of the reference building with and without daylighting scheme (with original lighting schedules) were compared. Figure 8 gives the annual lighting electricity consumption $(\mathrm{kWh})$, while Figure 9 presents the annual cooling energy consumption $(\mathrm{kWh})$. 


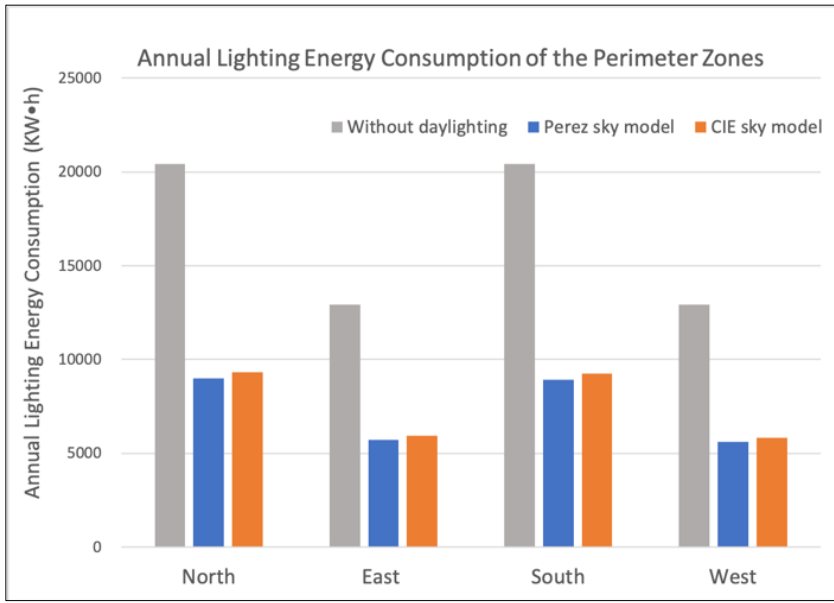

Figure 8: Annual lighting energy consumption of the four perimeter zones.

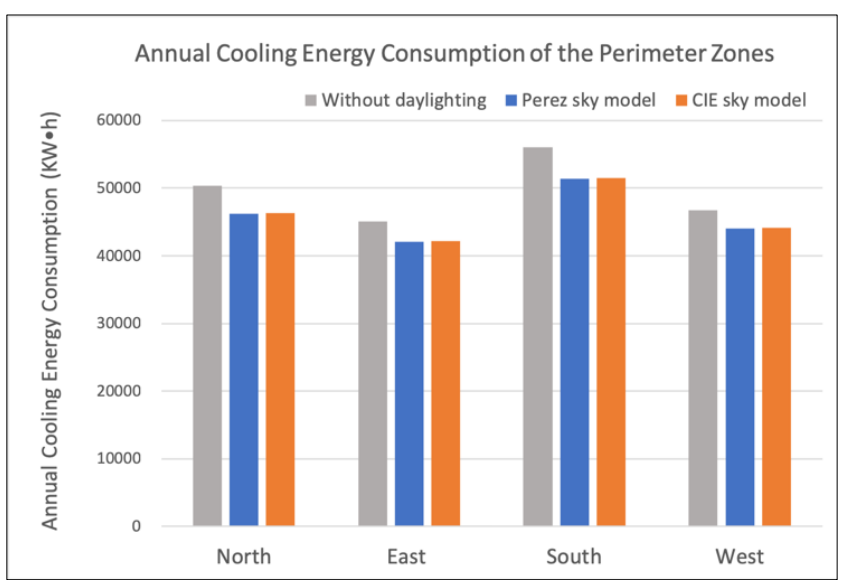

Figure 9: Annual cooling energy consumption of the four perimeter zones.

According to Figure 8 , more that $55 \%$ of the annual lighting electricity consumption can be reduced for each zone by dimming lighting controls. It indicates a large potential of energy saving can be achieved by various daylight-linked lighting control strategies. The lighting energy saving of the south zone is slightly larger than that of the north zone calculated based on both the two sky models. This is because the south zone is more accessible to the sunlight and thus obtaining more daylight which is greater that the target illuminance. For all the four directions, the energy savings calculated by the CIE sky model is smaller than that of the Perez sky model. According to Figure 9, this difference for the cooling energy saving seems to be neglectable. The largest cooling energy consumption of the south zones is because of the largest amount of heat gains caused by solar radiation. Around 9- to $9.5 \%$ of the total annual cooling energy consumption for each zone can be reduced by lighting controls. This could make an important contribution to the overall energy efficient building design.

Although the CIE sky model and the Perez model have similar performance for evaluate the lighting and cooling energy reduction potential of lighting controls, the CIE model has a better performance for predicting the vertical daylight illuminance. Since the indoor daylight level is largely determined by the vertical illuminance level received by the fenestration, the CIE model may be more suitable for indoor daylight determination and evaluating daylight-linked lighting control strategies. In addition, the coefficient of the CIE model are constants but the Perez model's coefficients depend on other parameters. Once the standard sky sets have been classified, the sky luminance distributions can be easily calculated. It indicates that the CIE model would be more applicable than the Perez model. Even with limited measurement of sky luminance data, there are various methods for classifying the CIE standard sky sets (Li et al., 2014).

\section{Conclusions}

The selection of different sky luminance distribution models for calculating the daylight illuminance is rarely considered in energy and daylighting simulations. In this study, two widely used sky luminance distribution models were evaluated and compared. Model performance was assessed in terms of vertical global illuminance, indoor daylight illuminance, lighting and cooling energy saving under corresponding lighting controls. The performance for predicting vertical illuminance was validated by measured data. Although similar performance of the two sky models were identified, the CIE model would be more convenient to be used once the sky conditions have been identified. More measured data of actual indoor daylight illuminance and lighting power consumption data should be analysed. Further work will focus on the evaluation of the sky luminance distribution models based on more recent long-term measurements and on the development of more applicable methods for sky classification. The CIE Standard Sky model is suggested to be incorporated to the present daylight and energy simulation software for facilitating the computational resources of lighting simulation. The findings of this work are significant for daylighting designs, lighting control system analyses and energy-efficient building evaluations.

\section{Acknowledgement}

Work described was fully supported by a Strategic Research Grant from the City University of Hong Kong (Project no. 7005036) and Wenqiang Chen was support by a City University of Hong Kong Studentship.

\section{References}

ASHRAE (2007). Energy Standard for Buildings Except Low-Rise Residential Buildings. Atlanta, GA.

Chow, S.K.H., Li, D.H.W., Lee, E.W.M. and Lam, J.C. (2013). Analysis and prediction of daylighting and energy performance in atrium spaces using daylightlinked lighting controls. Applied Energy 112, 10161024.

CIE (1994). Guide to recommended practice of daylight measurement (CIE 1994. 109), CIE Central Bureau, Vienna, Austria. 
CIE (2003). Spatial Distribution of Daylight - CIE Standard General Sky (CIE S 011/E:2003), CIE Central Bureau, Vienna, Austria.

Department of Energy (DOE), Office of Energy Efficiency and Renewable Energy, (2019). Commercial Reference Buildings. https://www.energy.gov/eere/buildings/commercialreference-buildings

Department of Energy's (DOE) (2019). EnergyPlus Software. https://energyplus.net

Electrical and Mechanical Services Department (EMSD) (2018), Code of Practice for Energy Efficiency of Building Services Installation. Hong Kong.

Electrical and Mechanical Services Department (EMSD) (2018). Hong Kong Energy End-use Data 2018. Hong Kong.

https://www.emsd.gov.hk/filemanager/en/content 76 2/HKEEUD2018.pdf

Kittler, R., Perez, R. and Darula, S. (1997). A new generation of sky standards. Proceedings of the LUX Europa Conference, Amsterdam. p. 359-373.

Li, D.H.W. (2010). A review of daylight illuminance determinations and energy implications. Applied Energy 87, 2109-2118.

Li, D.H.W., Lau, C.C.S and Lam, J.C. (2005). Predicting daylight illuminance on inclined surfaces using sky luminance data. Energy 30(9), 1649-1665.
Li, D.H.W., Yang, L. and Lam, J.C. (2013). Zero energy buildings and sustainable development implications A review. Energy 54, 1-10.

Li, D.H.W., Chau, T.C. and Wan, K.W. (2014), A review of the CIE general sky classification approaches. Renewable and Sustainable Energy Reviews 31, 563 574.

Li, D.H.W., Cheung, A.C.K., Chow, S.K.H. and Lam, J.C. (2015). Switching frequency and energy analysis for photoelectric controls, Building and Environment 85, 205-210.

Li, D.H.W. and Lou, S. (2018). Review of solar irradiance and daylight illuminance modeling and sky Classification. Renewable Energy 126, 445-453.

Perez, R., Seals, R. and Michalsky, J. (1993). All-weather model for sky luminance distribution-Preliminary configuration and validation. Solar Energy 50(3), 235-245.

Wang, H. and Zhai, Z. (2016). Advances in building simulation and computational techniques: A review between 1987 and 2014. Energy and Buildings 128, 319-335.

Ward, G. and Shakespeare, R., (1998). Rendering with Radiance: The Art and Science of Lighting Visualization. San Francisco: Morgan Kaufmann Publishers, Inc.

\section{Appendix}

Coefficients and descriptions of the 15 CIE standard skies

\begin{tabular}{|c|c|c|c|c|c|c|c|c|}
\hline Sky No. & $\begin{array}{c}\text { Gradiation } \\
\text { group }\end{array}$ & $\mathbf{a}$ & b & \begin{tabular}{|c|} 
Indicatrix \\
group
\end{tabular} & c & d & e & Description of luminance distribution \\
\hline 1 & 1 & 4 & -0.7 & 1 & 0 & -1 & 0 & $\begin{array}{l}\text { CIE standard overcast sky, steep luminance } \\
\text { gradation towards zenith azimuthal uniformity }\end{array}$ \\
\hline 2 & 1 & 4 & -0.7 & 2 & 2 & -1.5 & 0.15 & $\begin{array}{l}\text { Overcast, with steep luminance gradation and } \\
\text { slight brightening towards the sun }\end{array}$ \\
\hline 3 & 2 & 1.1 & -0.8 & 1 & 0 & -1 & 0 & $\begin{array}{l}\text { Overcast, moderately graded with azimuthal } \\
\text { uniformity }\end{array}$ \\
\hline 4 & 2 & 1.1 & -0.8 & 2 & 2 & -1.5 & 0.15 & $\begin{array}{l}\text { Overcast, moderately graded and slight } \\
\text { brightening towards the sun }\end{array}$ \\
\hline 5 & 3 & 0 & -1 & 1 & 0 & -1 & 0 & Sky of uniform luminance \\
\hline 6 & 3 & 0 & -1 & 2 & 2 & -1.5 & 0.15 & $\begin{array}{l}\text { Partly cloudy sky, no gradation towards zenith, } \\
\text { slight brightening towards the sun }\end{array}$ \\
\hline 7 & 3 & 0 & -1 & 3 & 5 & -2.5 & 0.3 & $\begin{array}{l}\text { Partly cloudy sky, no gradation towards zenith, } \\
\text { brighter circumsolar region }\end{array}$ \\
\hline 8 & 3 & 0 & -1 & 4 & 10 & -3 & 0.45 & $\begin{array}{l}\text { Partly cloudy sky, no gradation towards zenith, } \\
\text { distinct solar corona }\end{array}$ \\
\hline 9 & 4 & -1 & -0.55 & 2 & 2 & -1.5 & 0.15 & Partly cloudy, with the obscured sun \\
\hline 10 & 4 & -1 & -0.55 & 3 & 5 & -2.5 & 0.3 & Partly cloudy, with brighter circumsolar region \\
\hline 11 & 4 & -1 & -0.55 & 4 & 10 & -3 & 0.45 & White-blue sky with distinct solar corona \\
\hline 12 & 5 & -1 & -0.32 & 4 & 10 & -3 & 0.45 & CIE standard clear sky, low luminance turbidity \\
\hline 13 & 5 & -1 & -0.32 & 5 & 16 & -3 & 0.3 & CIE standard clear sky, polluted atmosphere \\
\hline 14 & 6 & -1 & -0.15 & 5 & 16 & -3 & 0.3 & Cloudless turbid sky with broad solar corona \\
\hline 15 & 6 & -1 & -0.15 & 6 & 24 & -2.8 & 0.15 & White blue turbid sky with broad solar corona \\
\hline
\end{tabular}

